\title{
REAPROVEITAMENTO DA CÂMARA DO PNEU DE BICICLETAS: parâmetros para corte e gravação a laser
}

\author{
Elisa Marangon Beretta \\ Feevale \\ elisamb@feevale.br \\ João Pedro Ornaghi de Aguiar \\ Feevale \\ joaoa@feevale.br \\ Marshal Becon Lauzer \\ Feevale \\ marshal@feelave.br \\ Júlia Isoppo Picolo \\ Feevale \\ juliai@feevale.br \\ Samira Moraes Troncoso Kroeff \\ Feevale \\ samirat@feevale.br
}

Resumo: O reaproveitamento de resíduos tem se tornado uma preocupação da sociedade atual, visando aplicar processos que resultem em novos produtos com os insumos descartados. Dentro dos resíduos mais poluentes, estão aqueles advindos da borracha sintética, que ainda tem em seu descarte como um problema. Um desses resíduos são as câmaras de pneus de bicicleta que, diferentemente dos carros, ainda fazem uso desse recurso para seu funcionamento. Com isso em mente, este trabalho teve como objetivo a transformação do resíduo da borracha de câmaras de pneus de bicicletas através do processo de corte e gravação a laser. Este processo pode gerar um maior valor agregado ao resíduo, melhorando seu acabamento em comparação aos processo de corte e gravação artesanais. Como metodologia, parâmetros de corte e gravação neste material foram testados. Os melhores resultados dos ensaios foram selecionados e aplicados em uma linha de acessórios. Como resultado, foi possível gerar uma coleção de pulseiras através do reaproveitamento da borracha de câmaras de pneus, além de dar ao resíduo um novo destino que não o descarte poluente.

Palavras-chave: corte e gravação a laser, borracha, aproveitamento de resíduos.

Abstract: The reuse of residues has become a major concern in society nowadays in order to implement objects that can result in new products with the inputs discarded. Within the dirtier residues are those that come from synthetic rubber, witch are still a problem. One of those residues is the chamber of bicycle tires that, differently from cars tires, still use chambers. With that in mind, this study aimed to transform the waste rubber chambers bicycle tires through cutting and laser engraving process. This process can generate a higher value to the residue, improving its finishing compared to handmade processes. As method, cut and engraving parameters were testes in rubber chambers. The best results were selected and applied as a line of accessories. As a result, it was possible to generate a 
collection of bracelets through out the reuse of rubber from bicycle tires chambers, in addiction to give the residue a new destination than the pollutant discard.

Key words: laser cut and engraving, rubber, waste recovery.

\section{INTRODUÇÃO}

Há uma grande preocupação na sociedade atual em reduzir resíduos e também aumentar o tempo de uso dos produtos. Campos (2006) afirma que, com a perturbação gerada pelo descarte de produtos em excesso e pela vasta extração de matérias-primas, cada fez é mais necessário que se atente ao ciclo de vida do produto, gerando leis que visem diminuir a exploração dos recursos naturais. Há algumas medidas governamentais que visam reduzir a extração e, por consequência, maximizar a vida útil dos aterros sanitários. No Brasil, uma das soluções que vem sido adotadas para atingir essa meta é a reutilização e reciclagem dos resíduos, aplicando alternativas tecnológicas, como destaca Rodrigues Jorge, Ferreira e Claro Neto (2004).

Já admite-se hoje que a melhor solução é o tratamento do resíduo, seja por reutilização ou reaproveitamento, e não apenas o descarte em local adequado, provendo um ganho ambiental para a sociedade (RODRIGUES JORGE, FERREIRA, CLARO NETO, 2004). Com esta ideia, os conceitos definidos como "poluidor-pagador" são reforçados, dando preferencia à reutilização do material e não a sua reciclagem, que também gera custos ambientais pelo reprocessamento (CAMPOS, 2006). Segundo Sousa, Oliveira e Cabral (2010), "a reutilização ou o reaproveitamento dos resíduos deve ser perseguida reencaixando-os numa nova cadeia produtiva".

Um dos resíduos poluentes bastante conhecidos são as borrachas sintéticas, de difícil reciclagem. Rodrigues Jorge, Ferreira e Claro Neto (2004) afirmam que os pneus podem causar diversos impactos ao meio ambiente. Um dos mais graves é o descarte em aterros sanitários, pois reduzem a vida útil dos mesmos por ter baixa compressibilidade. No entanto, a produção e consumo desses materiais ainda são altos, tendendo a aumentar ainda mais, com o estímulo cada vez maior para o uso da bicicleta como meio de transporte. Campos (2006) dá um panorama desse cenário, mostrando que "a produção mundial de borrachas, natural e sintética, é de cerca de 20 milhões de toneladas por ano, das quais quase $60 \%$ são utilizadas na manufatura de pneus e $75 \%$ do total tem como destino utilizações relacionadas com a indústria automóvel".

Uma das formas mais comuns de reciclagem dos pneus, com muitos estudos já realizados (KAMIMURA, 2002; RODRIGUES JORGE, FERREIRA, CLARO NETO, 2004; CAMPOS, 2006; SOUSA, OLIVEIRA, CABRAL, 2010), é agregar os mesmos em materiais de construção. Para realizar esse processo, Sousa, Oliveira e Cabral (2010) citam que é necessário triturar o pneu, gerando uma borracha granulada, e então adicioná-lo ao material de construção em questão. Também é necessário que ocorra a fusão entre esses dois materiais, originando um terceiro material.

Porém, essa reciclagem ainda possui um alto custo energético durante o processo e só utiliza os pneus de carros. Alguns subprodutos da borracha são deixados de lado, como as câmaras ainda utilizadas nos pneus da maioria das bicicletas. Uma das formas de dar um novo estudo a esses resíduos é o uso de uma tecnologia que gere um novo acabamento ao material que está desvalorizado, gerando um novo valor agregado ao produto.

\subsection{Corte e gravação à laser}

Segundo Cidade (2012), o laser (Light Amplified by Stimulated Emission Radiation) é "um instrumento de altíssima precisão geométrica, criando inúmeras aplicações às indústrias. Seu funcionamento baseia-se nas leis fundamentais da interação entre a radiação luminosa e a matéria". Essa tecnologia tem sido aplicada em diversos setores como a indústria têxtil, moveleira, calçadista e metal-mecânica, que vem utilizando esse instrumento em substituição as técnicas tradicionais de corte. (WIGGERS, 2006). Outras aplicações são comunicações por fibras ópticas, o registro de dados em CD, o corte de precisão e solda de materiais, a cirurgia ocular, a leitura de código de barras, a irradiação de fibras têxteis (ALONSO, 2008).

Essa tecnologia traz diversas vantagens como a "flexibilidade e capacidade de produção de cortes complexos, com boa produtividade e precisão" (WIGGERS, 2006), além de usar uma "tecnologia de corte sem ter contato direto com o material" (CHOUDHURY, SHIRLEY, 2010), que evita desgastes 
associados aos métodos com contato, prevenindo deformações e danos ao material (RASEIRA, 2013). Há algumas desvantagens no processo, como "o preço do equipamento e a impossibilidade de corte de várias camadas sobrepostas de tecido devido ao pequeno alcance do foco do laser" (VERDÉRIO, RUFFINO, 2001).

Um dos parâmetros trabalho pelo laser é a potência do feixe. Normalmente, cortes e perfurações necessitam de maior potencia para conseguir vaporizar o material. Já para o processo de gravação, uma potencia menor é requerida, para que apenas algumas camadas sejam retiradas (RASEIRA, 2013). Em tecidos, por exemplo, a gravação a laser pode retirar apenas algumas fibras. Esse processo pode ser usado para atingir um efeito desbotado e "usado", como sugerido no estudo de Kan, Yuen e Cheng (2010).

Assim, foi observado que a gravação e o corte a laser é uma opção para gerar novos produtos quando são desejados novos efeitos e tratamentos no material. No caso de resíduos, um novo acabamento pode tornar um material que seria descartado em um novo produto, aumentando seu ciclo de vida. Desta forma, este trabalho visa contribuir com novas alternativas tecnológicas para reuso da borracha advinda da câmara de pneus de bicicleta.

\section{DESENVOLVIMENTO}

A borracha butílica, que compõe a câmara que se encontra dentro de um pneu de bicicleta, é um material sintético cuja característica principal é a elasticidade e a capacidade de impedir a fuga de ar. A borracha de isobutileno isopreno, copolímero conhecido como borracha butílica, foi introduzida no mercado em 1942. É um composto polimerizado em solução de isobutileno em uma pequena percentagem de isopreno. A válvula, que permite controlar a pressão de dentro da câmara de ar, é fixada por um processo de vulcanização. Dependendo dos aditivos com que é fabricada a câmara, a borracha torna-se mais ou menos elástica. Esse aspecto da fabricação é utilizado por alguns fabricantes para alcançar um composto capaz de abranger tamanhos diferentes de pneus.

Para os testes de corte e gravação a laser foram recolhidas câmaras de pneu usadas em lojas que oferecem o serviço de manutenção de bicicletas. A variação entre produtos de fabricantes diferentes não parece oferecer mudanças significativas no setup da máquina. A máquina de corte e gravação a laser utilizada é do modelo HZC-1280, importada pela Garudan do Brasil. O laser é do tipo tubo de $\mathrm{CO} 2$, de 80 watts de potência, resfriado com água. A área de trabalho especificada pelo fabricante é de $1000 \mathrm{~mm}$ por $800 \mathrm{~mm}$.

\subsection{Ensaio de corte à laser}

Os ensaios de corte foram realizados em amostras da borracha cortadas da mesma câmara de pneu. Cada amostra media $220 \mathrm{~mm}$ de comprimento por $45 \mathrm{~mm}$ de largura. As câmaras de pneu contém uma espécie de talco que impede que as suas paredes internas se unam. Esse talco foi eliminado por limpeza mecânica simples. O padrão a ser cortado foi escolhido por simular aplicações em que os espelhos que projetam o laser têm gradativamente menos tempo para acelerar até a velocidade estabelecida. Quanto maior o segmento de reta a ser percorrido pelo laser antes de uma mudança de direção, maior é a possibilidade dele atingir sua velocidade final estabelecida pelos parâmetros. Isso implica que nos quadrados maiores a probabilidade de uma corte imperfeito (incapaz de atravessar a borracha) seja maior, uma vez que o laser passou mais tempo atuando na velocidade escolhida entre dois vértices do quadrado. A probabilidade de um corte imperfeito em um quadrado pequeno é menor uma vez que a velocidade média é mais baixa, tendo o laser mais tempo de atuar e segmentar o material. Foram realizados, em sequência, os testes descritos no Quadro 1.

Quadro 1 - Parâmetros utilizados para corte

\begin{tabular}{|l|c|c|c|c|}
\hline & Amostra A & Amostra B & Amostra C & Amostra D \\
\hline Potência & $99 \%$ & $99 \%$ & $99 \%$ & $99 \%$ \\
\hline Velocidade & $15 \%$ & $20 \%$ & $35 \%$ & $80 \%$ \\
\hline Potenciômetro & $100 \%$ & $100 \%$ & $50 \%$ & $100 \%$ \\
\hline Modo & Corte & Corte & Corte & Corte \\
\hline
\end{tabular}

Fonte: Elaborado pelos autores, com base na pesquisa realizada. 
Estes quatro testes buscaram apontar os parâmetros limite de corte da borracha, ou seja, a velocidade máxima em que o laser ainda era capaz de cortar toda a espessura da borracha. Essa informação é relevante, pois evita o desperdício de potência do laser e garante a eficiência do processo, tornando-o o mais rápido possível dentro do resultado esperado. Na Figura 1 é possível perceber que a velocidade é baixa o suficiente para realizar o corte na potência máxima da máquina. 0 quadrado médio não foi completamente cortado por ter saído do foco do laser devido a uma ondulação da borracha. Mesmo assim concluiu-se que é possível aumentar a velocidade do laser a fim de diminuir o tempo necessário para a obtenção do resultado esperado, aumentando assim a eficácia do processo.

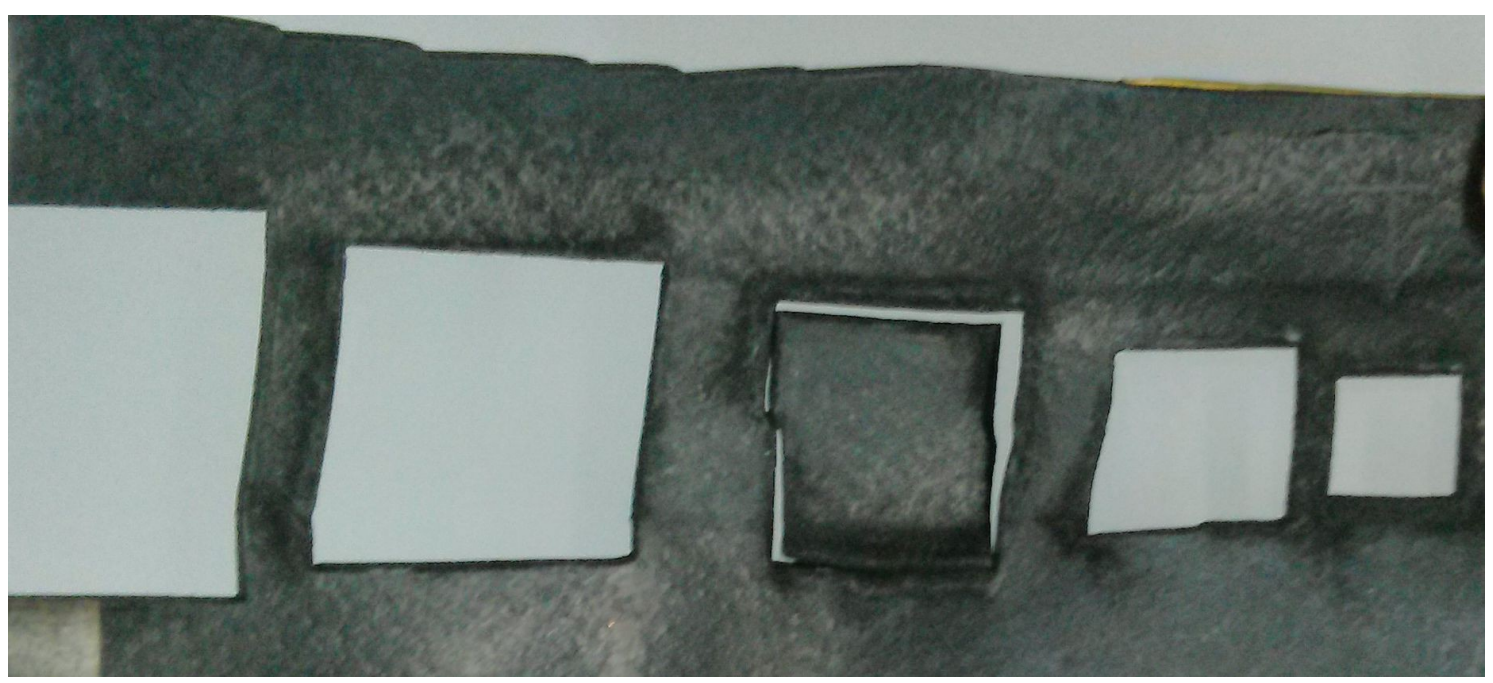

Figura 1 - Amostras A - Corte

Fonte: Elaborado pelos autores, com base na pesquisa realizada.

A Amostra B (Figura 2) provou que a velocidade poderia se ainda mais alta mantendo a segmentação desejada do material.

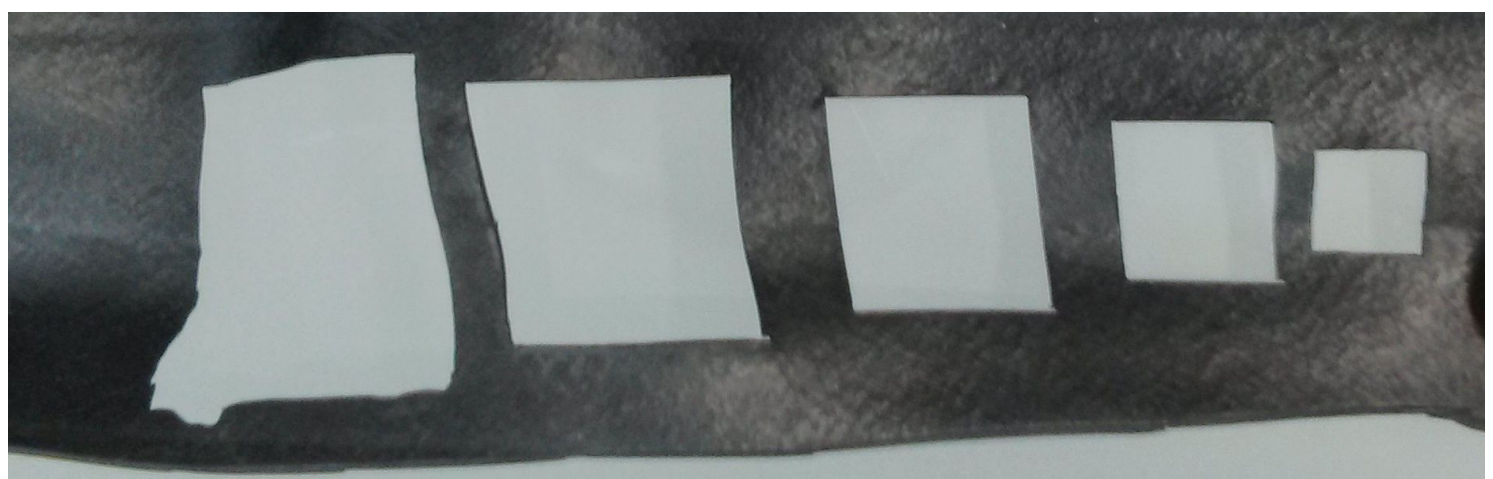

Figura 2 - Amostras B - Corte

Fonte: Elaborado pelos autores, com base na pesquisa realizada.

Já na Amostra C (Figura 3) os quadrados internos do padrão cortado na borracha não se destacaram totalmente, mas puderam ser soltos ao serem tracionados levemente. A velocidade escolhida (35) é capaz de realizar o corte quase completo mesmo nos segmentos grandes, a dificuldade maior, como previsto, ficou restrita aos segmentos maiores, nas trajetórias retilíneas. Vale ressaltar que este teste foi feito com o potenciômetro da máquina ajustado a $50 \%$. Esse ajuste fino visa prevenir o desgaste do laser. 


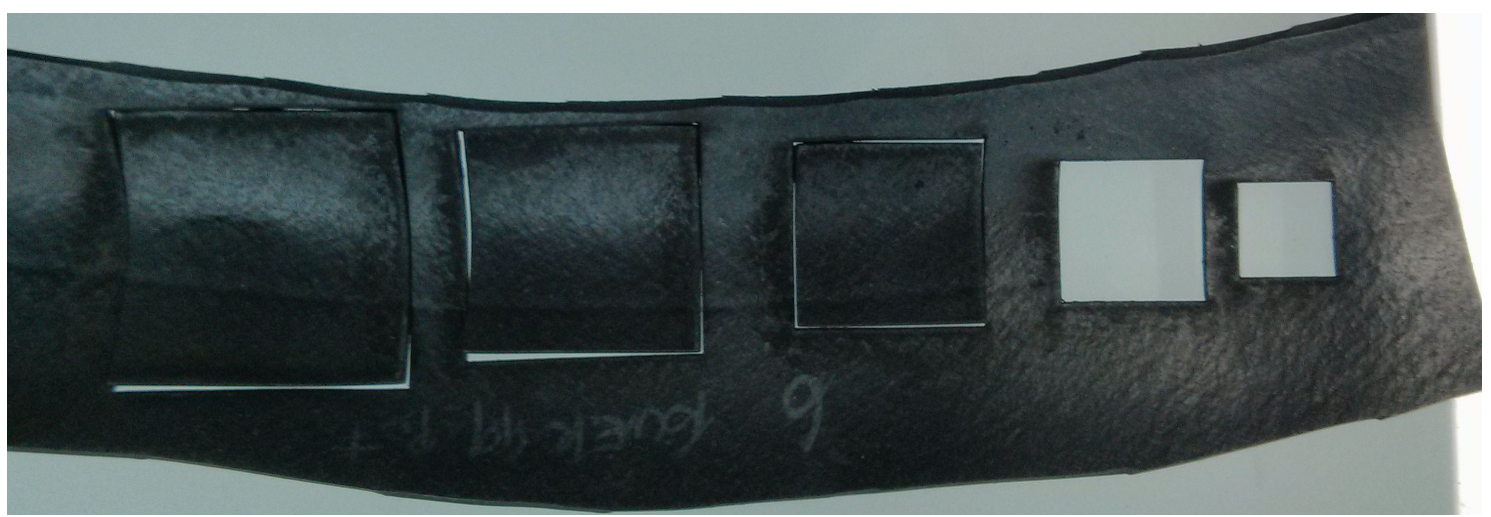

\section{Figura 3 - Amostras C - Corte}

Fonte: Elaborado pelos autores, com base na pesquisa realizada.

A última amostra (Amostra D - Figura 4) serviu para assegurar que velocidades altas (80 ou mais) não são capazes de cortar o material de forma desejada. É possível verificar que mesmo no quadrado médio, o segmento reto não foi cortado plenamente. E o maior quadrado apresentou impossibilidade de separar a peça a mão.

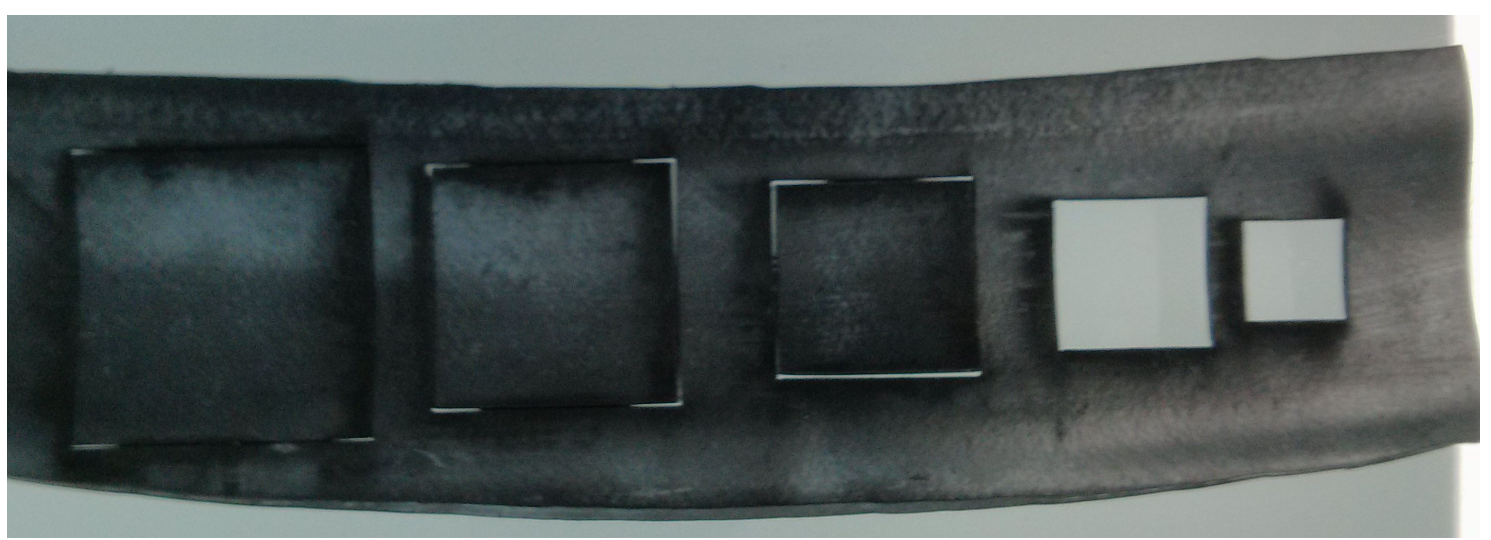

Figura 4 - Amostras D - Corte

Fonte: Elaborado pelos autores, com base na pesquisa realizada.

\subsection{Ensaio de gravação à laser}

Os ensaios de gravação foram realizados em amostras similares às amostras de corte, com borracha retirada da mesma câmara de pneu. Cada amostra media $220 \mathrm{~mm}$ de comprimento por $45 \mathrm{~mm}$ de largura. Estes corpos de teste foram limpos da mesma forma que aqueles utilizados para os testes de corte. Foram realizados, em sequência, os testes descritos no Quadro 2.

Quadro 2 - Parâmetros utilizados para agravação

\begin{tabular}{|l|l|l|l|}
\hline & Amostra A & Amostra B & Amostra C \\
\hline Potência & $50 \%$ & $60 \%$ & $60 \%$ \\
\hline Velocidade & $100 \%$ & $100 \%$ & $100 \%$ \\
\hline Potenciômetro & $50 \%$ & $50 \%$ & $50 \%$ \\
\hline Passo & $0,15 \mathrm{~mm}$ & $0,2 \mathrm{~mm}$ & $0,35 \mathrm{~mm}$ \\
\hline Modo & Gravação & Gravação & Gravação \\
\hline
\end{tabular}

Fonte: Elaborado pelos autores, com base na pesquisa realizada.

Na Figura 5 pode-se observar os efeitos da variação dos parâmetros na área gravada das amostras. A variação entre as amostras concentrou-se no passo para a gravação. Essa escolha justificase pela busca do maior passo que permita a percepção de que a área gravada é diferente a área original. Quanto maior o passo, mais rápida é a gravação da área escolhida. A potência definida foi mantida em 
$50 \%$ e $60 \%$ uma vez que a profundidade da gravação estava adequada ao resultado esperado visualmente.
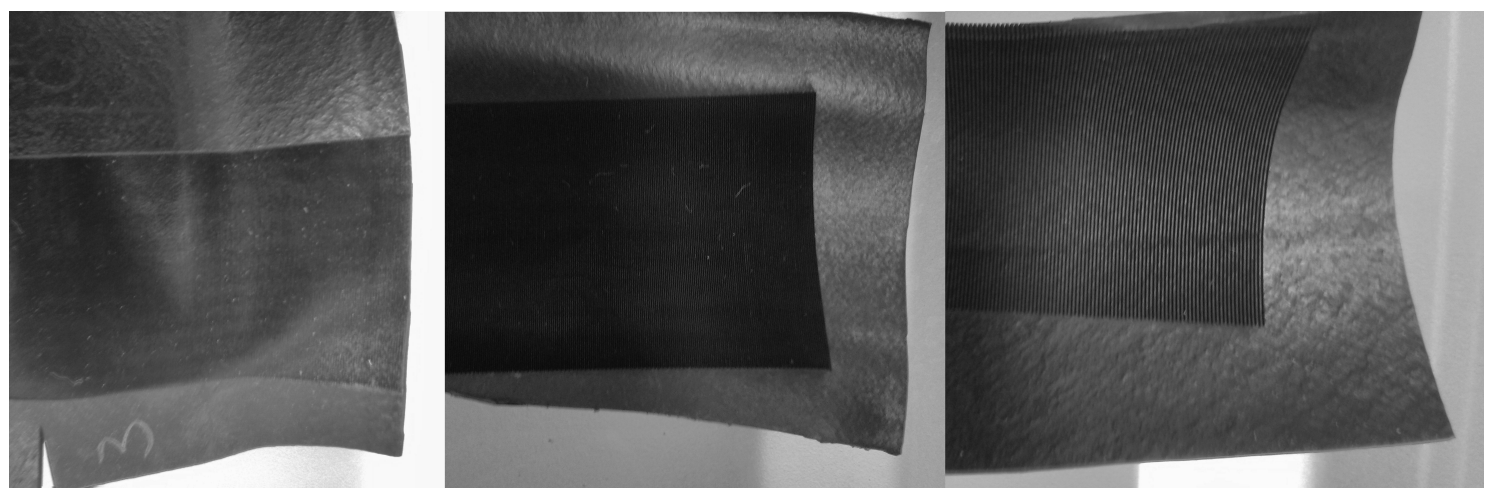

Figura 5 - Amostras A, B e C - Gravação

Fonte: Elaborado pelos autores, com base na pesquisa realizada.

\subsection{Ensaio de gravação nas pulseiras}

Tanto os parâmetros de corte quanto os de gravação foram utilizados nos testes realizados para comparar o efeito da variação da potência e da velocidade do laser no aspecto final da borracha. A variação no passo (deslocamento lateral do componente movido) da "cabeça" de corte/gravação foi utilizada para gerar efeitos durante a gravação. Um valor de 0,35 $\mathrm{mm}$ de passo resultou em um aspecto aveludado na borracha (visível na Figura 5, amostra C). Esse aspecto conseguido através da gravação foi utilizado como inspiração para a sugestão de uma linha de pulseiras femininas que visam agregar valor às câmaras de pneu descartadas. Na Figura 6 pode-se visualizar um padrão projetado com objetivo de gerar um desenho na superfície através de diferentes cores. Assim, a gravação foi programada para tirar algumas camadas de material, dando aspecto de diferentes tonalidades, sendo a mais escura a área afetada pelo laser.

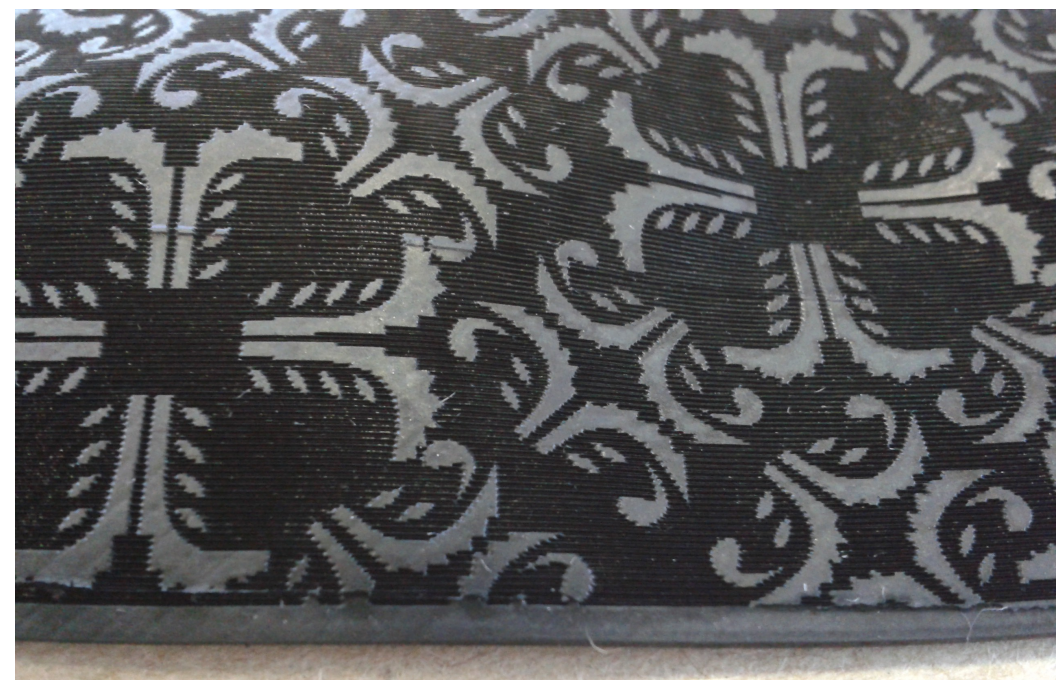

Figura 6 - Detalhe do aspecto aveludado

Fonte: Elaborado pelos autores, com base na pesquisa realizada.

Como aplicação do corte, foi feito um modelo com pequenos detalhes. Os parâmetros utilizados foram $99 \%$ de potencia, $35 \%$ de velocidade de corte e potenciômetro do equipamento a $50 \%$. Os resultados foram satisfatórios conforme a Figura 7. As geometrias cortadas eram pequenas e se destacaram com facilidade da peça. Além disso, a superfície não apresentou rebarbas, dispensando qualquer tipo de acabamento posterior. 


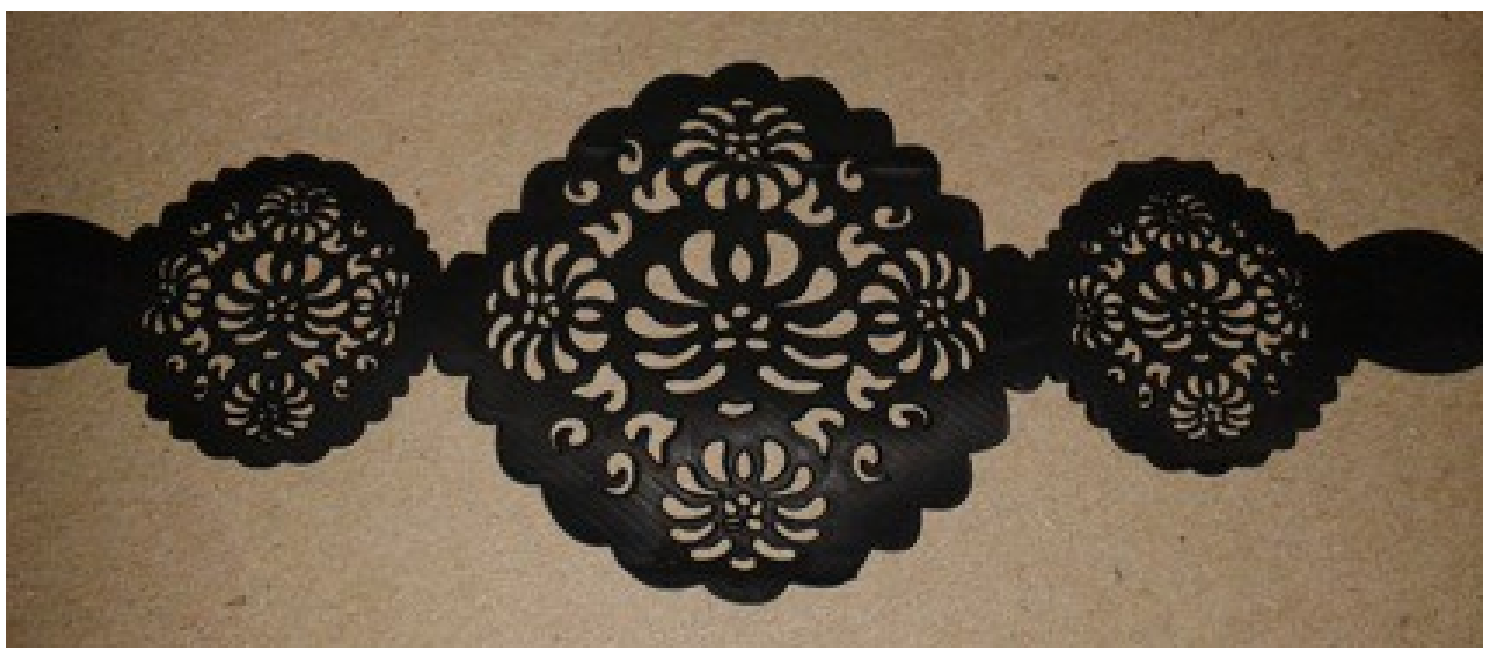

Figura 7 - Pulseira gerada com o corte a laser

Fonte: Elaborado pelos autores, com base na pesquisa realizada.

Uma das pulseiras cortadas apresentou um problema no corte. A forma desenhada possuía pequenos detalhes nas bordas (Figura 8), o que deixou o material mais frágil, suscetível a rasgos. Assim, foi detectado que é necessário fazer uma borda fechada nos desenhos para dar maior resistência à peça.

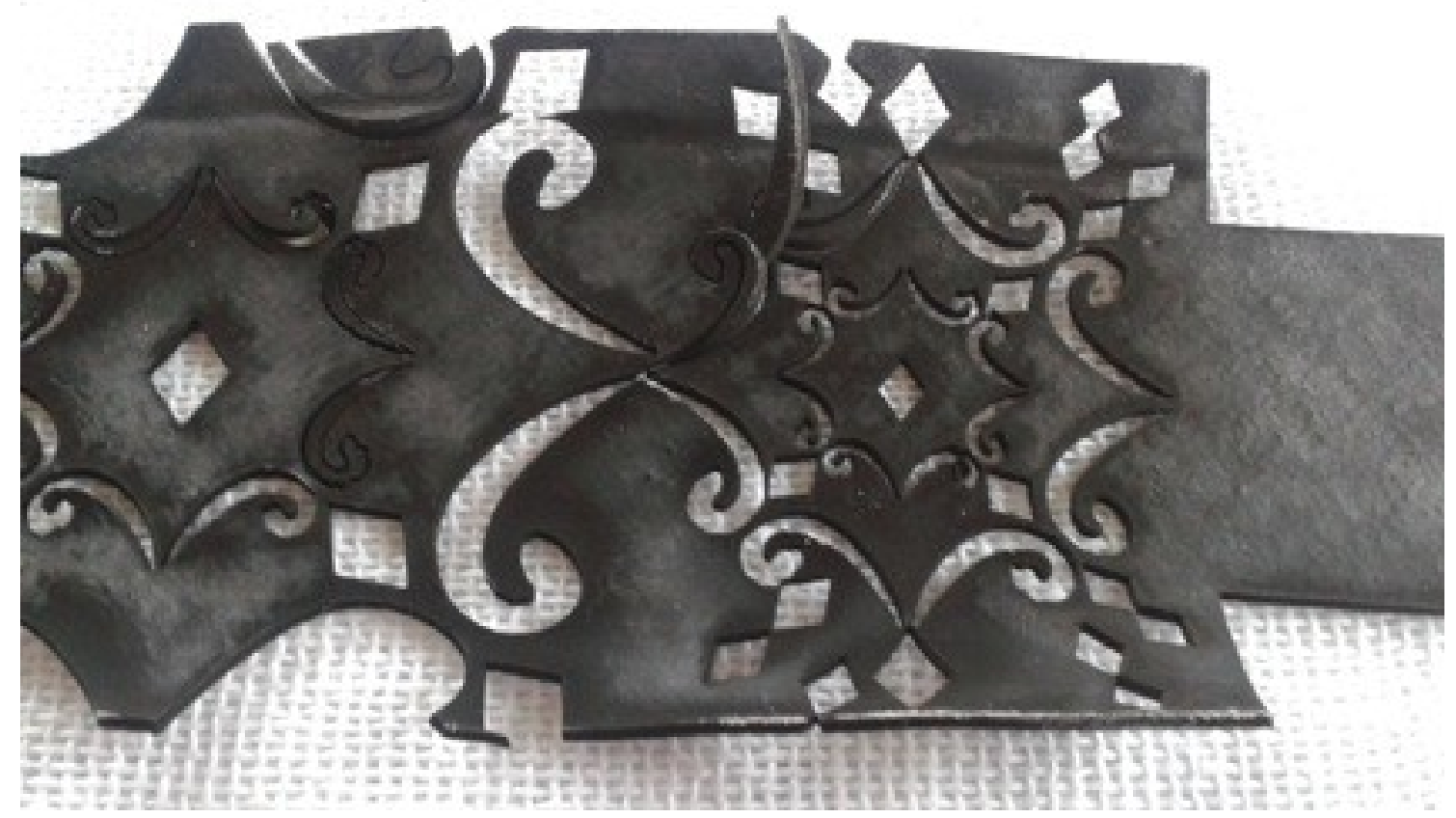

Figura 8 - Detalhe do corte na pulseira, deixando o material suscetível a rasgos

Fonte: Elaborado pelos autores, com base na pesquisa realizada.

Foram gerados outros modelos de pulseiras, que apresentaram resultados similares aos apresentados, como na Figura 9, onde pode-se visualizar a gravação de detalhes na superfície e, em outra peça, o corte de detalhes. Ainda é possível gerar peças que façam uso de ambas as técnicas, misturando desenhos com corte e gravação. 

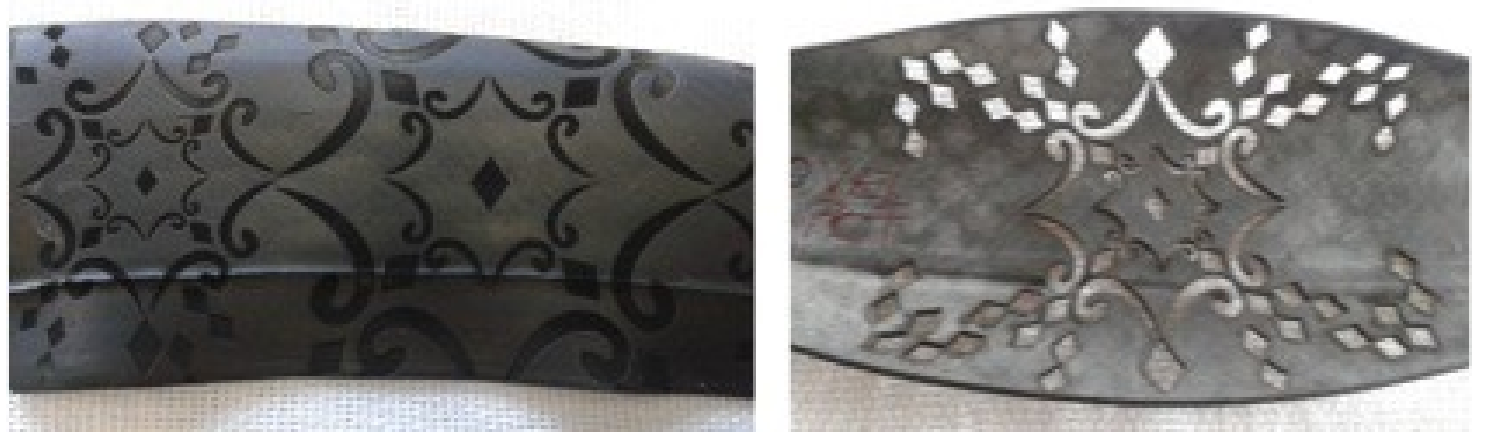

Figura 9 - Detalhe do corte na pulseira, deixando o material suscetível a rasgos

Fonte: Elaborado pelos autores, com base na pesquisa realizada.

\section{CONCLUSÃO}

A busca por parâmetros que contemplem eficiência e velocidade para assegurar o fator econômico na produção com a qualidade estética pretendida em um acessório feminino, resultou em uma indicação de velocidade, potência e passo para corte e gravação a laser de borracha de câmara de pneu usada. A limitação da borracha de câmara de pneu ao ser submetida ao laser está na presença de ondulações que podem alterar o foco do laser, diminuindo a qualidade da peça. Com esse estudo, foi possível observar que a técnica de corte a laser pode gerar um maior valor agregado ao resíduo, dando um novo ao fim que não o descarte poluente.

Como trabalhos futuros sugere-se que novas formas de emular efeitos visuais e táteis na borracha e em outros materiais sejam pesquisados. A tentativa de simular características de outro material (p. ex. veludo na borracha) justifica-se quando da necessidade de identificação do consumidor com um material proveniente de descarte.

\section{REFERÊNCIAS}

ALONSO; Helena Sofia Moreira Pereira. Estudo do efeito do tratamento por laser de CO2 nas propriedades superficiais de fibras sintéticas. 2008. 109 f. Dissertação (Mestrado) - Universidade do Minho. Programa de Pós-Graduação em Química Têxtil.

CAMPOS, Paulo da Silva. Aproveitamento Industrial da Borracha Reciclada de Pneus Usados. Dissertação (mestrado). 2006. 157 f. Universidade do Minho - Pós-graduação em Gestão Ambiental.

CHOUDHURY, I. A.; SHIRLEY, S. Laser cutting of polymeric materials: An experimental investigation. Optics \& Laser Technology 42, 2010, P. 503-508.

CIDADE, Mariana Kuhl. Caracterização e padronização do processo de gravação a laser em ágata aplicado ao design de joias. 2012. 172 f. Dissertação (Mestrado) - Universidade Federal do Rio Grande do Sul, Programa de Pós-Graduação em Design.

KAMIMURA, Eliane. Potencial de utilização dos resíduos de borracha de pneus pela indústria da construção civil. 2002. 128 f. Universidade Federal de Santa Catarina - Programa de Pós-Graduação em Engenharia Civil.

KAN, C. W.; YUEN, C. W. M.; CHENG, C. W. Technical study of the effect of CO2 laser surface engraving on the colour properties of denim fabric. Color Technology 126, 2010, P. 365-371.

RASEIRA, Cristine Bassols. Design e Tecnologia aplicados a Resíduos de Madeira: Especificações para o Processo de Corte a Laser em Marchetaria. 2013. 168 f. Dissertação (Mestrado) - Universidade Federal do Rio Grande do Sul, Programa de Pós-Graduação em Design.

RODRIGUES JORGE, Mara Regina Pagliuso; FERREIRA, Osny Pellegrino; CLARO NETO, Salvador. Aproveitamento da borracha de pneus inservíveis na produção de componentes para construção. In: Congresso Brasileiro de Ciência e Tecnologia em Resíduos e Desenvolvimento Sustentável. Florianópolis, 2004.

SOUSA, Maressa Soares de; OLIVEIRA, lara Silvia Rodrigues de; CABRAL, Adeildo da Silva. Utilização do resíduo de desemborrachamento de pistas de aeronaves na produção de blocos de concreto para 
pavimentação. In: 3o Simposio Iberoamericano de Ingeniería de Residuos / 20 Seminário da Região Nordeste sobre Resíduos Sólidos. Ceará, 2010.

VERDÉRIO; Leonardo Aparecido; RUFFINO, Rosalvo Tiago. Corte de têxteis por meio de um processo híbrido mecânico-térmico. In: $\mathbf{1}^{\circ}$ Congresso Brasileiro de Engenharia de Fabricação. Curitiba, 2001.

WIGGERS, Ricardo Hawerroth. Controle de movimento para máquina de corte a laser com acionamento por correias. Dissertação (mestrado). 2006. 65 f. Programa de Pós-Graduação em Engenharia Elétrica, Universidade Federal de Santa Catarina. 